\title{
Implication of frequency-dependent protocols in antiarrhythmic and proarrhythmic drug testing
}

\author{
Péter P. Nánási a, b, 1 , Zoltán Szabó ${ }^{\text {c, } 1}$, Kornél Kistamás a , Balázs Horváth ${ }^{a}$, László Virág ${ }^{\text {d, e }}$, \\ Norbert Jost ${ }^{\mathrm{d}, \mathrm{e}, \mathrm{f}}$, Tamás Bányász ${ }^{\mathrm{a}}$, János Almássy a, ${ }^{\mathrm{a}}$, András Varró ${ }^{\mathrm{d}, \mathrm{e}, \mathrm{f}, \text {, *, } 2}$ \\ a Department of Physiology, Faculty of Medicine, University of Debrecen, Debrecen, Hungary \\ b Department of Dental Physiology, Faculty of Dentistry, University of Debrecen, Debrecen, Hungary \\ ${ }^{c}$ Department of Emergency Medicine, Faculty of Medicine, University of Debrecen, Debrecen, Hungary \\ ${ }^{\mathrm{d}}$ Department of Pharmacology and Pharmacotherapy, Faculty of Medicine, University of Szeged, Szeged, Hungary \\ e Department of Pharmacology and Pharmacotherapy, Interdisciplinary Excellence Centre, University of Szeged, Szeged, Hungary \\ ${ }^{\mathrm{f}}$ MTA-SZTE Research Group for Cardiovascular Pharmacology, Szeged, Hungary
}

\section{A R T I C L E I N F O}

\section{Article history:}

Received 1 October 2019

Received in revised form

30 October 2019

Accepted 1 November 2019

Available online $\mathrm{xxx}$

\section{Keywords:}

Cardiac myocytes

Cardiac arrhythmias

Action potential duration

Cardiac ion currents

Rate-dependent actions

Reverse rate-dependency

Short term variability

Triggered activity

\begin{abstract}
A B S T R A C T
It has long been known that the electrophysiological effects of many cardioactive drugs strongly depend on the rate dependent frequency. This was recognized first for class I antiarrhythmic agents: their $V_{\text {max }}$ suppressive effect was attenuated at long cycle lengths. Later many $\mathrm{Ca}^{2+}$ channel blockers were also found to follow such kinetics. The explanation was provided by the modulated and the guarded receptor theories. Regarding the duration of cardiac action potentials (APD) an opposite frequency-dependence was observed, i.e. the drug-induced changes in APD were proportional with the cycle length of stimulation, therefore it was referred as "reverse rate-dependency". The beat-to-beat, or short term variability of APD (SV) has been recognized as an important proarrhythmic mechanism, its magnitude can be used as an arrhythmia predictor. SV is modulated by several cardioactive agents, however, these drugs modify also APD itself. In order to clear the drug-specific effects on SV from the concomitant unspecific APDchange related ones, the term of "relative variability" was introduced. Relative variability is increased by ion channel blockers that decrease the negative feedback control of APD (i.e. blockers of $\mathrm{I}_{\mathrm{Ca}}, \mathrm{I}_{\mathrm{Kr}}$ and $\mathrm{I}_{\mathrm{Ks}}$ ) and also by elevation of cytosolic $\mathrm{Ca}^{2+}$. Cardiac arrhythmias are also often categorized according to the characteristic heart rate (tachy- and bradyarrhythmias). Tachycardia is proarrhythmic primarily due to the concomitant $\mathrm{Ca}^{2+}$ overload causing delayed afterdepolarizations. Early afterdepolarizations (EADs) are complications of the bradycardic heart. What is common in the reverse rate-dependent nature of drug action on APD, increased SV and EAD incidence associated with bradycardia.
\end{abstract}

(c) 2019 Elsevier Ltd. All rights reserved.

\section{Contents}

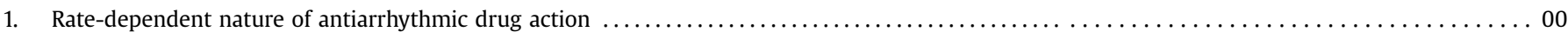

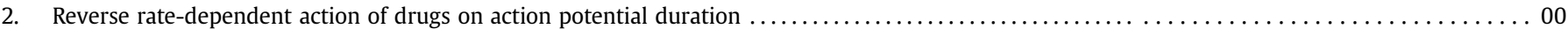

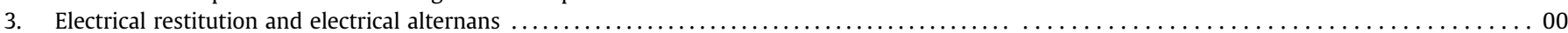

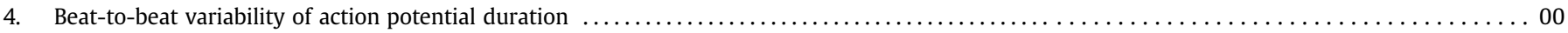

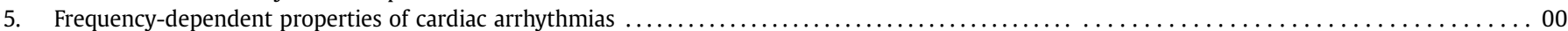

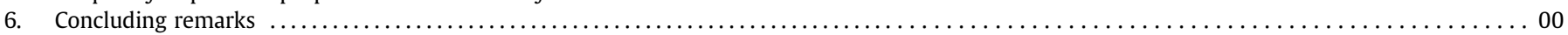

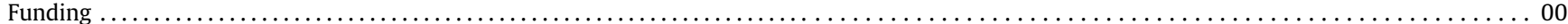

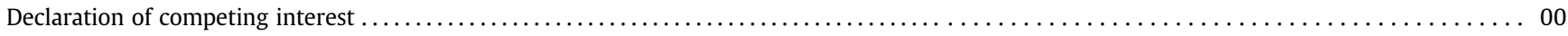

\footnotetext{
* Corresponding author. Department of Pharmacology and Pharmacotherapy, University of Szeged, Szeged, Hungary.

E-mail address: varro.andras@med.u-szeged.hu (A. Varró).

1 Drs Nánási and Szabó Contributed equally to this work. Both are to be considered first authors.

2 Drs Almássy and Varró Share senior authorship.
} 


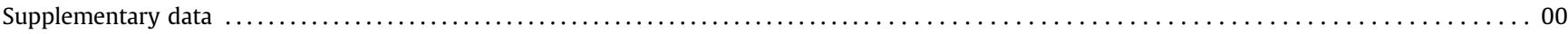

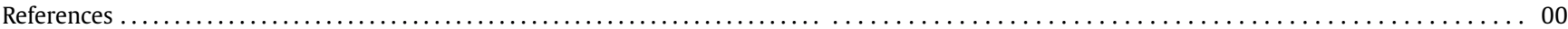

\section{Rate-dependent nature of antiarrhythmic drug action}

Ignorance of the rate-dependent nature of cardioactive drug actions was the reason for many malpractice cases when class $1 / \mathrm{C}$ antiarrhythmics were applied in acute cardiac infarct patients. As we know from the CAST Study application of $1 / \mathrm{C}$ drugs, like flecainide or encainide, increased the mortality comparing to patients not treated with these agents (Echt et al., 1991). It turned out that 1/ $\mathrm{C}$ antiarrhythmics ( $\mathrm{Na}^{+}$-channel inhibitors particularly) have very slow offset kinetics resulting in the blockade of normally coupled action potentials too in addition to suppression of early prematures. Subclassification of class I antiarrhythmics is usually done by their offset kinetics; in other words, by the time constant of recovery from reduction in upstroke velocity $\left(\mathrm{V}_{\max }\right)$ block caused by the agent following high frequency stimulation (Campbell, 1983). Using this approach 1/B drugs (mexiletine, lidocaine and tocainide) were characterized with the fastest offset kinetics ranging within a few hundreds of milliseconds. 1/A compounds have somewhat slower offset kinetics: in the range of a few seconds, while in the case of 1/ $C$ drugs the time course of offset is extended to more than $10 \mathrm{~s}$. In accordance with this behaviour, the frequency-dependence of various class I antiarrhythmics are different under steady-state conditions as well, since drugs having fast offset kinetics are more active at rapid heart rates and can selectively block premature extra action potentials without suppressing the propagation of normal action potentials (antiarrhythmic effect). In contrast, drugs with slow kinetics cause a marked steady-state block at normal heart rates increasing the risk of re-entry arrhythmias due to development of conduction block (Campbell, 1992).

The rate-dependent nature of the effects of class I antiarrhythmics is based on their rate-dependent interaction with fast $\mathrm{Na}^{+}$ channels which are responsible for the rapid action potential upstroke, determining this way the intraventricular conduction velocity. At a molecular level the modulated receptor hypothesis provides an explanation for the rate-dependent drug action (Hondeghem and Katzung, 1984). The central point of this theory is the assumption that the various channel states (resting, open and inactivated) have different affinity to bind the antiarrhythmic drug and the drug-binding channel state in not conductive (Hille, 1977). Consequently, at higher rate dependent frequency the relative contribution of the open and inactivated channel population increases in line with the stronger rate-dependent (also called usedependent) inhibition. An alternative explanation for the ratedependent blockade is provided by the guarded receptor theory (Grant et al., 1984; Starmer and Grant, 1985). This argumentation is based on the assumption that a charged (or hydrophilic) antiarrhythmic compound can access and leave its binding site through the hydrophilic conducting pore, which is guarded by the closed gates (Starmer et al., 1984). Consequently, both association and dissociation of drug to/from its binding site is possible only when the channel is in open state. Both models are in accordance with the voltage-dependent nature of $\mathrm{Na}^{+}$channel blockade demonstrated under voltage clamp conditions and allow differentiation between open channel block in the case of quinidine, and inactivated channel block in the case of lidocaine (Hondeghem and Katzung, 1977; Colatsky, 1982; Hondeghem and Matsubara, 1988). The guarded receptor theory predicts that channels equipped with inactivation gates can be inhibited in a rate-dependent manner provided that the blocker molecule is charged. Indeed, various blockers of the L-type cardiac $\mathrm{Ca}^{2+}$ channels (class IV antiarrhythmics, including verapamil derivatives and dihydropyridines) were also reported to show the phenomenon of rate-dependent inhibition (Hondeghem and Katzung, 1984). Accordingly, it appears that the rate-dependent nature of the channel-drug interaction may be a general property of drugs acting on cardiac ion channels.

\section{Reverse rate-dependent action of drugs on action potential duration}

It has to mentioned that physiologically at fast heart rate APD is short and as heart rate slows down, APD lengthens producing an exponential like curve called recently dynamic restitution curve (Osadchii, 2017).

In sharp contrast with the use-dependent $\mathrm{Na}^{+}$channel blockade and $\mathrm{V}_{\max }$ suppression caused by class I antiarrhythmics, the repolarization lengthening effect of class III drugs (including $\mathrm{K}^{+}$-channel inhibitors particularly) increases with the increase of the pacing cycle length, ie. by slowing of the heart rate. Since class III antiarrhythmics act by increasing the refractory period due to prolongation of action potential duration (APD) this means that the APD lengthening effect of these agents is augmented at lower frequencies. This "reverse rate-dependent" behavior was initially observed with blockers of the rapid delayed rectifier $\mathrm{K}^{+}$current (Jurkiewicz and Sanguinetti, 1993), however, it was observed with many other agents that cause lengthening of APD. Unfortunately, the reverse rate-dependency is therapeutically unfavourable because the beneficial drug effect is relatively small at shorter cycle lengths, while the incidence of early afterdepolarizations is increased at normal or longer cycle lengths, which effect is known to be proarrhythmic (Hondeghem and Snyders, 1990; Nair and Grant, 1997; Weirich and Antoni, 1998). This may explain the disappointing results obtained with selective $\mathrm{I}_{\mathrm{Kr}}$ inhibitor $\mathrm{d}$-sotalol, which increased the mortality of myocardial infarct patients in the SWORD Study (Waldo et al., 1995). Recently a strong reverse rate dependent effect of $\mathrm{I}_{\mathrm{Kr}}$ current blockers was also observed in human induced pluripotent stem cell-derived cardiomyocytes (hiPSCCMs) (Lemoine et al., 2018).

Several hypotheses were developed so far to explain the mechanism of the reverse rate-dependence, including the accumulation of $\mathrm{I}_{\mathrm{Ks}}$ due to incomplete channel deactivation at short cycle length (Jurkiewicz and Sanguinetti, 1993), the accumulation of $\mathrm{K}^{+}$ions in the extracellular clefts (Yang and Roden, 1996), frequency-dependent changes in action potential configuration (Rocchetti et al., 2001; Virág et al., 2009), and the modulated receptor theory with the hypothesized reduction of drug binding to open channel state. These explanations were able to partially explain the reverse rate-dependent property of $\mathrm{I}_{\mathrm{Kr}}$ blockers, however, failed to provide convincing explanation for the general feature of reverse rate-dependency.

Zaza suggested first that reverse rate dependency is a general largely species independent phenomenon as a consequence of nonlinearity of the $\mathrm{dV} / \mathrm{dt}$ versus APD relationship (Zaza and Varró, 2006; Zaza, 2010). As demonstrated in Fig. 1.A,B, drugs known to either lengthen or shorten APD develop more pronounced effects on APD at longer than at shorter cycle length (Bányász et al., 2009; Zaza, 2010). It has also been shown that the phenomenon is really a 


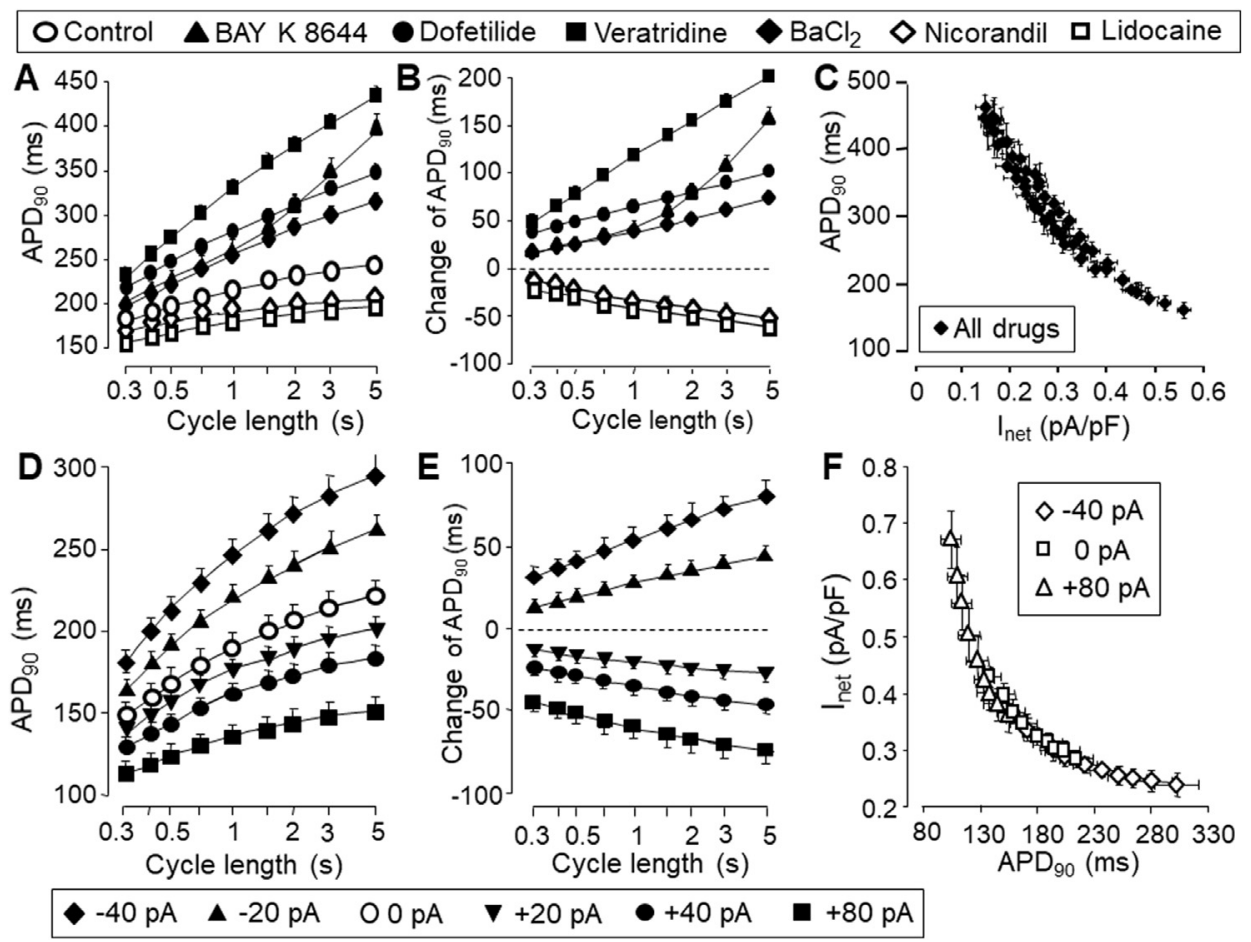

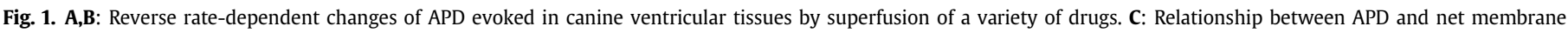

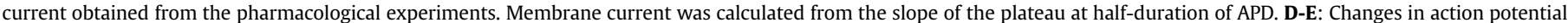
duration induced with inward and outward current pulses. F: Current-APD relationship obtained from the experiments using current injections.

general property of heart tissues derived from a variety of species, including canine, guinea pig and human cardiac preparations (Bárándi et al., 2010a). Finally, experiments performed in rabbits and rats revealed the critical point, since APD changes biphasically with cycle length in rabbit, while in rat there is a relatively flat APD or QTc versus CL relation (Mulla et al., 2018) or an inverse relationship between APD and the stimulation cycle length (Nánási et al, 1996). Drug actions on APD in both rabbits and rats were proportional with APD rather than with the pacing cycle length (Bárándi et al., 2010a, 2010b). These results clearly indicate that the action of any drug on APD is stronger when the APD is long (usually at longer cycle lengths in larger mammals) because the net membrane current flowing during the plateau phase of the action potential is smaller under these conditions. Consequently, any given change in the plateau current (evoked by a drug action) is expected to cause a relatively larger shift in APD as demonstrated in Fig. 1.C. Strong support of this theory is provided by the data presented in Fig. 1.D-F, where drug actions were mimicked by using inward and outward current pulses in order to lengthen and shorten APD, respectively. Although the shapes of the curves are not fully identical for drug and current applications, the reverse rate-dependent character of the changes is evident in both cases. In summary, the inverse relationship between APD and net plateau current may be mainly responsible for the reverse rate-dependency (Fig. 1.C and 1.F).

\section{Electrical restitution and electrical alternans}

To critically study both antiarrhythmic and proarrhythmic properties of a certain drug the electrical restitution properties of cardiac tissues should be also considered. The standard (distinguishable from dynamic) electrical restitution curves can be defined by the relation of the APD lengthening of extra beats $\left(S_{2}\right)$ by gradually increasing the coupling or diastolic intervals from a constant basic cycle length $\left(\mathrm{S}_{1}-\mathrm{S}_{1}\right)$. As seen in Fig. $2 \mathrm{~A}$ APD is gradually increased (steepened APD restitution) as diastolic interval increases. This phenomenon and its role in arrhythmogenesis including its pharmacological modulation (Varro et al., 1985; Garfinkel et al., 2000; Wu et al., 2002) had been described long time ago (Boyett and Jewell, 1978; Elharrar and Surawicz, 1983; Robinson et al., 1987; Nash et al., 2006; Pak et al., 2004), but its significance in arrhythmogenesis gained also particular attention in the last decade (Osadchii, 2017; Shattock et al., 2017).

According to the APD restitution hypothesis, by gradual increase of the diastolic or coupling intervals due to the propagation of an extra beat, the next possible extra beat would encounter longer APD and ERP and as a consequence, local conduction block or wave break can occur. If the electrical restitution curve is steeper, it would favour such an effect and impediment of local impulse propagation ie. conduction block may occur. This is considered to be proarrhythmic (Garfinkel et al., 2000; Osadchii, 2017). In the contrary flattened restitution curve should have an opposite consequence. Regional difference in the electrical restitution curves (Morgan et al., 1992; Riccio et al., 1999; Boukens et al., 2017) can also favour arrhythmogenesis (Osadchii, 2017). As Fig. 2B shows restitution properties are markedly different in physiological condition between ventricular and Purkinje fibres, therefore this aspect, and its influence on arrhythmogenesis and possible antiarrhythmic actions should be studied more intensively in the future.

It had been reported that certain antiarrhythmic drugs decreased the slope of APD restitution (flattened APD restitution) in both cardiac Purkinje (Varró et al, 1985) and ventricular (Garfinkel et al., 2000) muscle (Fig. 3). APD alternans (Fig. 3) also relates to electrical restitution in the sense that steeper restitution curve facilitates its appearance (Weiss et al, 2011, 2015). When fast sudden changes in constant frequency (dynamic restitution) happen, its first beat interval can result shorter APD due to short coupling or 

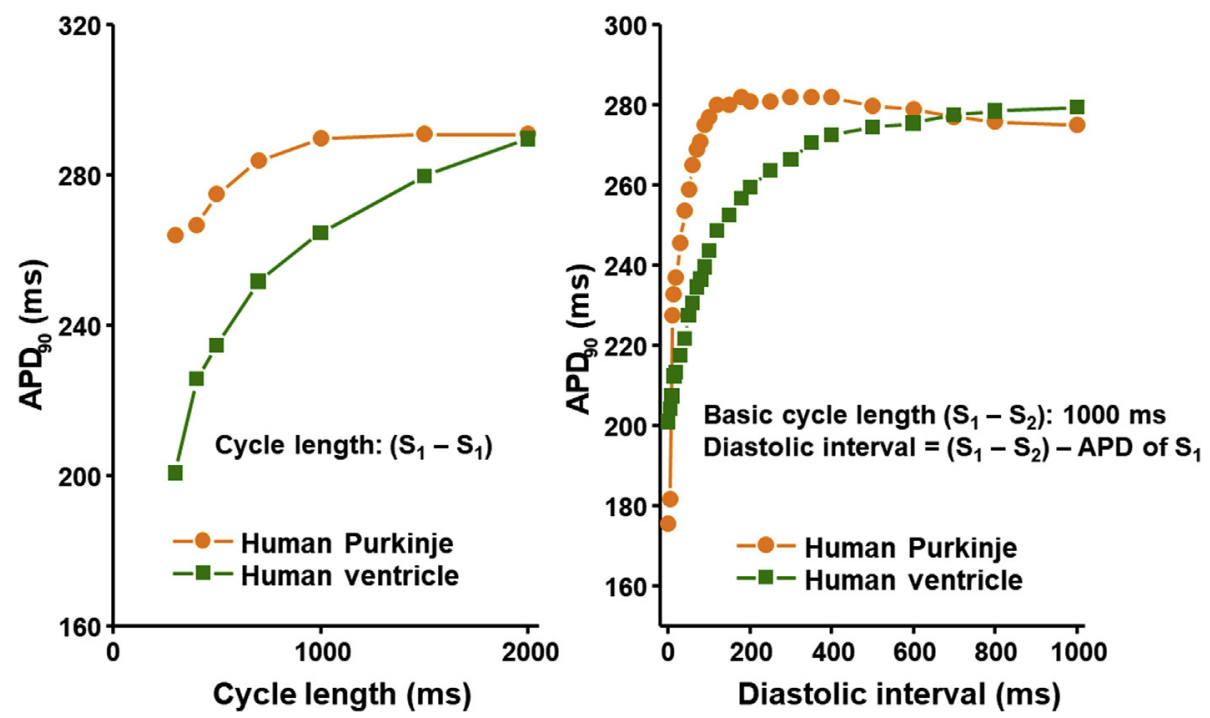

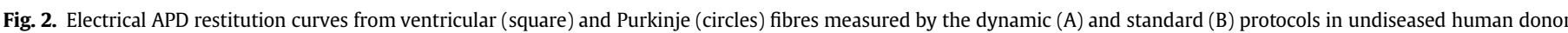

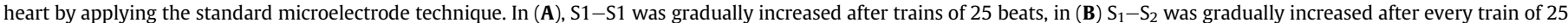
beats from basic cycle length (S1-S1) of $1000 \mathrm{~ms}$ (unpublished results from Department of Pharmacology and Pharmacotherapy, University of Szeged).
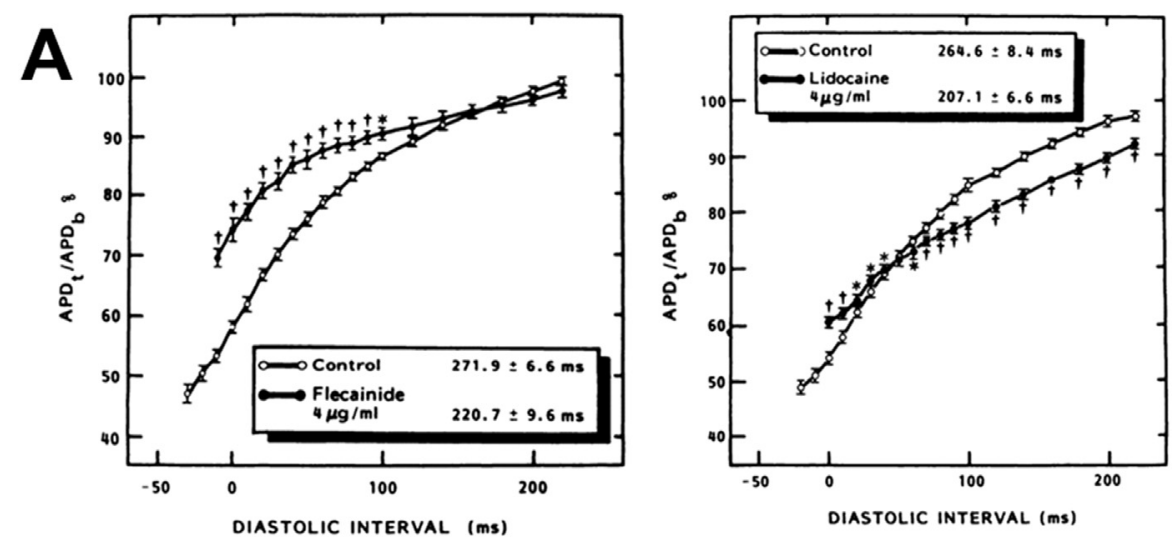

B

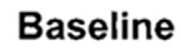

\section{Bretylium}
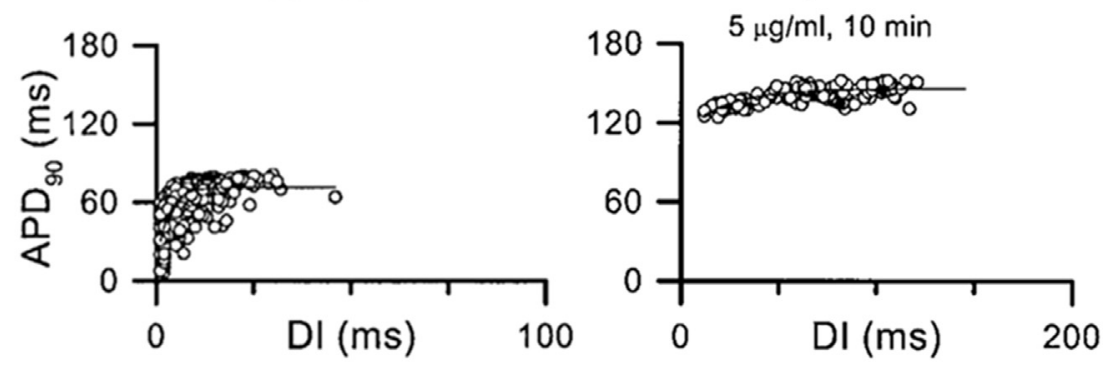

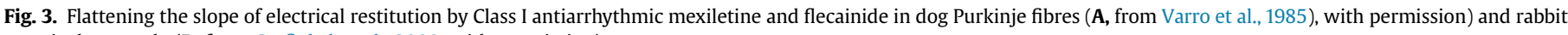
ventricular muscle (B, from Garfinkel et al., 2000, with permission).

$\mathrm{APD}_{\mathrm{t}}=$ action potential durations of extrasystoles with increasing D1 (test)

$\mathrm{APD}_{\mathrm{b}}=$ action potential durations of basic cycle length.

diastolic interval, which would consequently results longer coupling or diastolic interval for the next beat, resulting longer APD and if this continues a short-long-short-long APD pattern, called action potential alternans would develop. It is possible that each action potential is simultaneously shortened or prolonged in all sites (concordant alternans, Fig. 4A). However, further increase of stimulation frequency so called discordant APD alternans (Fig. 4B) can be developed when APDs at further distance or regions can alternate with opposite phases markedly increasing dispersion of repolarization and consequently enhancing substrate for arrhythmias (Pastore et al., 1999). Therefore, applying the dynamic restitution protocols ie. gradually decreasing steady state pacing cycle lengths until ERP is achieved can be a useful protocol to detect both proarrhythmic and antiarrhythmic drug actions. 


\section{A}

Spatially Concordant alternans

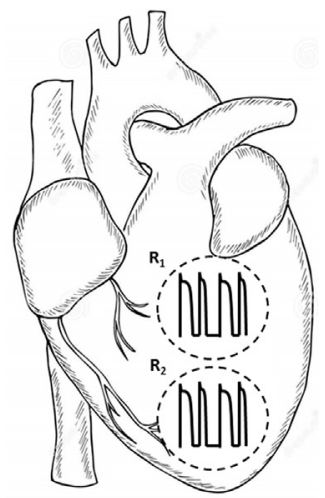

B

Spatially Discordant alternans

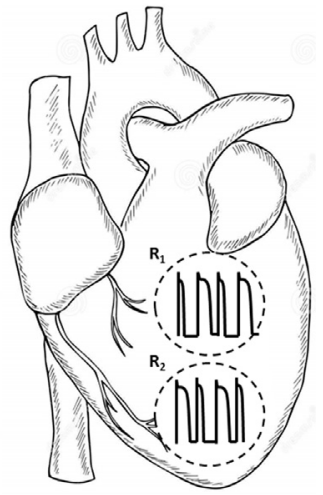

Fig. 4. Electrical concordant (A) and discordant (B) alternans. Detailed explanation in the text at paragraph entitled "Electrical restitution and electrical alternans".

The ion channel background of the frequency dependent APD changes regardless of the fact whether the dynamic or standard restitution protocols are used -including electrical alternans-can be attributed to the not fully recovery from inactivation and deactivation of different inward currents such $\mathrm{I}_{\mathrm{Na}}$ and $\mathrm{I}_{\mathrm{Ca}}$ or outward currents such as $\mathrm{I}_{\mathrm{to}}, \mathrm{I}_{\mathrm{Kr}}$, $\mathrm{I}_{\mathrm{Ks}}$ and $\mathrm{I}_{\mathrm{Cl}}$ depending on the gating properties of these channels (Ni et al., 2018; Tolkacheva et al., 2006). Also intracellular ion concentration changes for $\mathrm{Ca}^{2+}$ and $\mathrm{Na}^{+}$can activate electrogenic $\mathrm{Na}^{+}-\mathrm{Ca}^{2+}$ exchanger (NCX) and $\mathrm{Na}^{+} / \mathrm{K}^{+}$pump with different time course as frequency changes result noticeable alterations in the extracellular $\mathrm{K}^{+}$-concentration in the clefts resulting changes both in depolarizing and repolarizing ionic currents.

Electrical alternans can also arise from frequency dependent properties of $\mathrm{Ca}^{2+}$-handling. At fast pacing amplitude of the intracellular $\mathrm{Ca}^{2+}$-transient can start alternating which than converts into repolarization alternans due to the function of NCX and other possible $\mathrm{Ca}^{2+}$-sensitive currents. Coupling between $\mathrm{Ca}^{2+}$ and repolarization alternans can be intrinsically bidirectional, but some studies suggest that $\mathrm{Ca}^{2+}$ alternans is the primarily course (Díaz et al., 2004; Pruvot et al., 2004). The mechanism underlying $\mathrm{Ca}^{2+}$ alternans can be attributed to the combination of steep SR load release relationship and insufficient SR refilling time.

\section{Beat-to-beat variability of action potential duration}

Incidence of cardiac arrhythmias depend on the simultaneous presence of a substrate and a trigger. In light of this it is not surprising that arrhythmia propensity is also rate-dependent, since both the duration of the refractory period, which is strongly dependent on APD, as well as the chance of development of electrical inhomogeneity are rate-dependent. A prominent component of temporal inhomogeneity is the beat-to-beat variability of APD, called also as short term variability (SV). The phenomenon has been studied in a variety of cardiac preparations including the human heart (Zaniboni et al., 2000; Hinterseer et al., 2008, 2009; AbiGerges et al., 2010; Sur et al., 2013), and it was found that elevation of SV is definitely proarrhythmic. Furthermore, SV is considered as one of the best arrhythmia predictors (Thomsen et al., 2004, 2006; Tereshchenko et al., 2010; Hinterseer et al., 2010; Jacobson et al., 2011). Several factors are involved in the modulation of SV, like the density and stochastic behavior of transmembrane ion channels (Lemay et al., 2011; Pueyo et al., 2011; Szentandrássy et al., 2015), intensity of cell-to-cell coupling (Zaniboni et al., 2000;
Magyar et al., 2015), action potential duration and morphology (Heijman et al., 2013), stimulation frequency (Johnson et al., 2010) and intracellular calcium handling (Johnson et al., 2013; Kistamás et al., 2015).

The major concern with simple determination of the magnitude of SV, which can easily be calculated and visualized using the Poincare plot (Van der Linde et al., 2005; Johnson et al., 2010), is that almost all the interventions used to modulate SV are known to change APD as well. This is problematic because SV is a sharp function of APD itself as demonstrated in Fig. 5.A,B. The specific actions of drugs or interventions on SV can be studied exclusively when SV data are cleared from the consequences of the concomitant APD changes. This is achieved by introducing the term of relative variability (RV), when the drug induced change in SV is evaluated in light of the APD change (Szentandrássy et al., 2015; Magyar et al., 2016). Accordingly, data points appear above the solid curve of the conventional SV-APD relationship indicate elevated RV values, while those located under the curve correspond to reduction of RV (Fig. 5.A,B). This concept of RV allows identification of the individual cardiac ion currents influencing RV (Fig. 5.D,E). Accordingly, suppression of $\mathrm{I}_{\mathrm{Kr}}, \mathrm{I}_{\mathrm{Ks}}, \mathrm{I}_{\mathrm{Ca}}$ increased $\mathrm{RV}$ (similar effects were observed with inhibition of $\mathrm{I}_{\mathrm{Cl}}$ and $\mathrm{I}_{\mathrm{NCX}}$ ) suggesting that these currents keep RV at a low level under physiological conditions (Szentandrássy et al., 2015). Indeed, inhibition of $\mathrm{I}_{\mathrm{Kr}}$ and $\mathrm{I}_{\mathrm{Ks}}$ were shown to increase beat-to-beat variability, while it was decreased by augmentation of $\mathrm{I}_{\mathrm{Ks}}$ (Lengyel et al., 2007; Johnson et al., 2010). In contrast, after blocking of $\mathrm{I}_{\mathrm{Na}} \mathrm{RV}$ was reduced indicating that $\mathrm{I}_{\mathrm{Na}}$ increases RV physiologically (Szentandrássy et al., 2015). Since $I_{C a}$, $\mathrm{I}_{\mathrm{Kr}}$ and $\mathrm{I}_{\mathrm{Ks}}$ are the major ion currents responsible for the negative feedback regulation of APD, their normal activity is essential for keeping $\mathrm{RV}$ at a reasonably low level. Similarly, $\mathrm{Ca}^{2+}$-dependent $\mathrm{Cl}^{-}$ current can stabilize APD when the intracellular $\mathrm{Ca}^{2+}$ level $\left(\left[\mathrm{Ca}^{2+}\right]_{i}\right)$ is elevated (Horváth et al., 2016; Hegyi et al., 2017). The other important factor known to modify $\mathrm{RV}$ is $\left[\mathrm{Ca}^{2+}\right]_{i}$ and the amplitude of the $\left[\mathrm{Ca}^{2+}\right]_{i}$ transient (Kistamás et al., 2015a). This is shown in Fig. 5.F, where elevation of $\left[\mathrm{Ca}^{2+}\right]_{i}$ using a $\mathrm{Ca}^{2+}$-ionophore compound increased, while its reduction by the $\mathrm{Ca}^{2+-}$ chelator BAPTA reduced RV. Similar effects were observed after blocking the activity of sarcoplasmic reticulum (SR) with ryanodine or CPA. It is likely, therefore, that the elevation of SV observed at high rate dependent frequencies are related to the concomitant $\left[\mathrm{Ca}^{2+}\right]_{\mathrm{i}}$ accumulation (Fig. 5.C, Kistamás et al., 2015a). Further factors, like an oxidative milieu, high temperature, or application of single cells instead of multicellular preparations were also shown to increase RV (Kistamás et al., 2015b), while the ß-adrenergic receptor agonist isoproterenol resulted a reduction of RV - probably due to the intensification of $\mathrm{I}_{\mathrm{Ca}}, \mathrm{I}_{\mathrm{Ks}}$ and $\mathrm{I}_{\mathrm{Kr}}$.

\section{Frequency-dependent properties of cardiac arrhythmias}

One classification of arrhythmias is based on the experience that both tachycardia and bradycardia are proarrhythmic conditions. Elevation of heart rate (often as a consequence of the increased sympathetic activity) results is $\mathrm{Ca}^{2+}$ overload of the cells. For a limited period of time this extra calcium can be sequestrated in the $\mathrm{SR}$ and mitochondria. Sustained mitochondrial $\mathrm{Ca}^{2+}$ influx may interfere with ATP production resulting in insufficient $\mathrm{Na}^{+}$removal, which is converted to further accumulation of $\mathrm{Ca}^{2+}$ via the $\mathrm{Na}^{+}$, $\mathrm{Ca}^{2+}$ exchanger (Bers, 2000). Within a certain number of cardiac cycles SR also will be overloaded with $\mathrm{Ca}^{2+}$ initiating a spontaneous $\mathrm{Ca}^{2+}$ release, since this is the only way for the overloaded SR (as well as for the cardiac myocyte) to get rid of the extra $\mathrm{Ca}^{2+}$ using the $\mathrm{Na}^{+} / \mathrm{Ca}^{2+}$ exchanger. The inward current generated by $\mathrm{Na}^{+} /$ $\mathrm{Ca}^{2+}$ exchanger causes transient depolarization of the cell membrane, typically following terminal repolarization, called therefore 

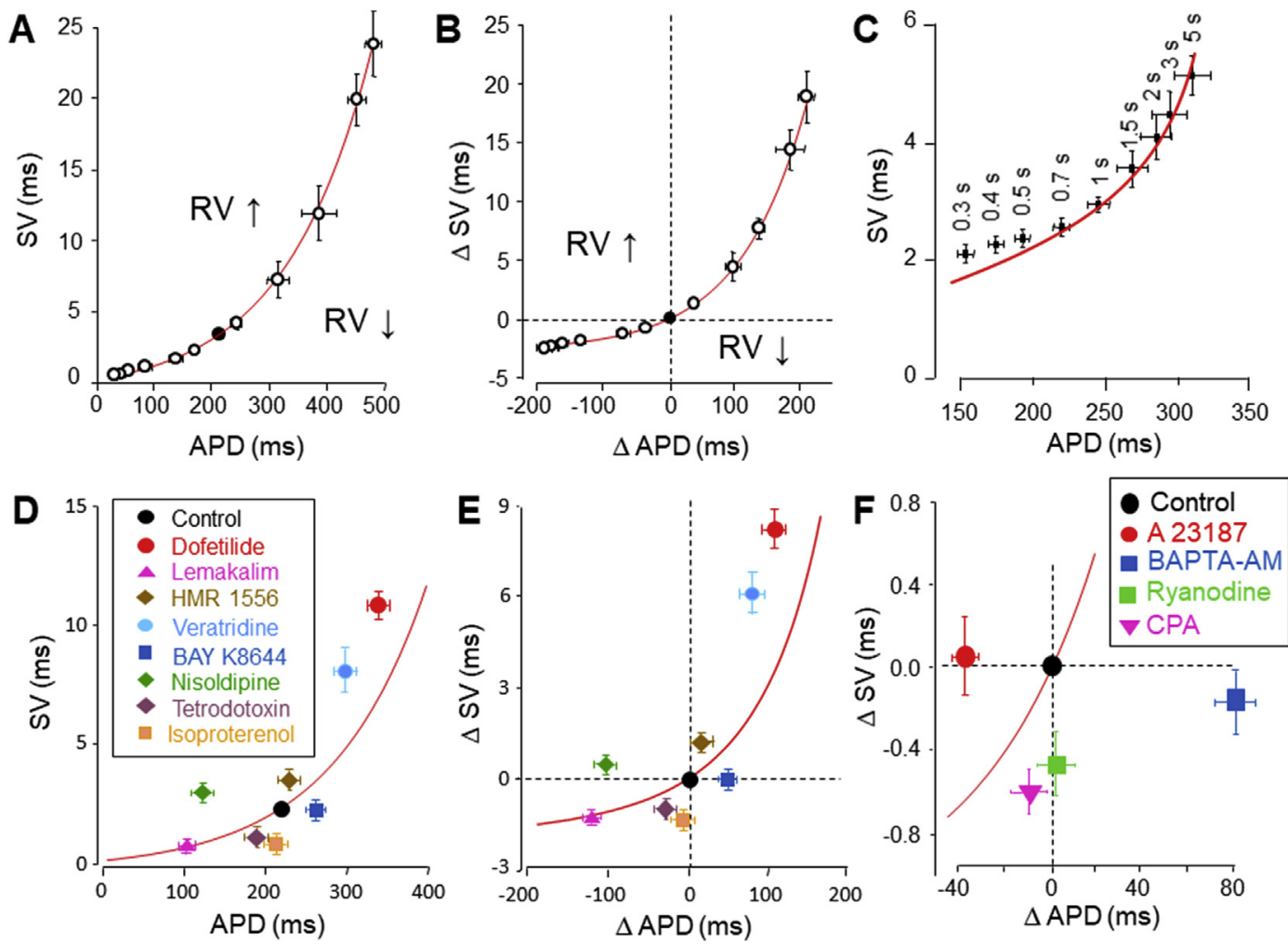

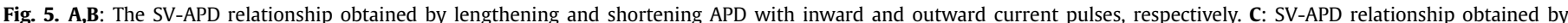

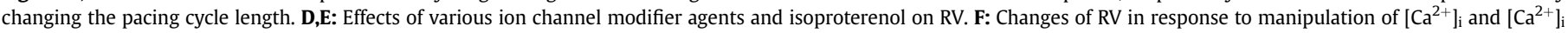

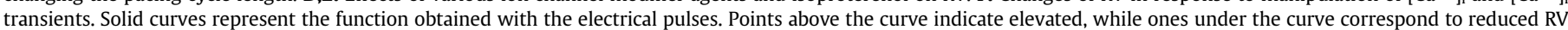
values.

delayed afterdepolarization, DAD (Hoffmann and Rosen, 1981). DADs may stimulate the neighbouring myocytes resulting in extrasystoles (trigger). In addition to these changes, elevated $\left[\mathrm{Ca}^{2+}\right]_{\mathrm{i}}$ leads to reduction of conduction velocity (substrate) due to the closure of gap junctions, increasing thus the probability of re-entry arrhythmias.

When the heart rate is low, the relative contribution of the refractory period to the whole cardiac cycle is diminished, also favouring to development of re-entry. More importantly, APD is concomitantly lengthened at low heart rates. This prolongation of APD allows the reactivation of inward currents, like $I_{C a}$, which may cause a second transient depolarization before terminal repolarization (Fozzard, 1992). Early afterdepolarizations (EADs) may act as a trigger to initiate extrasystoles. The incidence of EADs is elevated in case of an imbalance between inward and outward currents causing an inward shift of net membrane current during the plateau. As shown in Fig. 1.C and 1.F, this is the case also when APD increases, i.e. when the net outward current is reduced. Under these conditions the substrate is the increased electrical instability during the plateau phase, reflected also by the increased beat-tobeat variability of APD, resulting larger temporal inhomogeneity.

\section{Concluding remarks}

The most important implication of the normal and reverse ratedependent nature of cardioactive drug action is that a wide range of stimulation frequency has to be tested when an agent acting on a cardiac ion channel is characterized electrophysiologically. A further problem arises from the large differences between the normal heart rate in humans and the rapid spontaneous frequency of the smaller laboratory animals, like rats, mice, guinea pigs and rabbits, typically used for drug studies. Therefore, larger mammals, like dogs or cats, may likely provide more relevant data. Thirdly, we have to realize that the normal heart rate of an animal, including humans, has been largely optimized by the evolution. Changes in heart rate to either direction may increase arrhythmia propensity. This may help to understand the reasons of the disappointing outcomes of the CAST and SWORD studies, and more importantly, may help to prevent similar pitfalls in the future.

Although all details of the frequency-dependent aspects of antiarrhythmic and proarrhythmic mechanisms is not fully explored at present, it is clear that all they show rate-dependent properties. By application of frequency-dependent experimental protocols less rate-dependent complications with the new antiarrhythmic agents are anticipated.

\section{Funding}

This work was funded by the National Research Development and Innovation Office (NKFIH K115397, K-119992 and GINOP-2.3.2.15-2016-00040), the Ministry of Human Capacities Hungary (20391-3/2018/FEKUSTRAT and EFOP-3.6.2-16-2017-00006) and by the Thematic Excellence Programme of the Ministry for Innovation and Technology in Hungary (ED_18-1-2019-0028), within the framework of the Space Sciences thematic programme of the University of Debrecen. The GINOP and EFOP projects are co-financed by the European Union and the European Regional Development Fund.

\section{Declaration of competing interest}

The authors declare no conflict of interest. 
Appendix A. Supplementary data

Supplementary data to this article can be found online at https://doi.org/10.1016/j.pbiomolbio.2019.11.001.

\section{References}

Abi-Gerges, N., Valentin, J.P., Pollard, C.E., 2010. Dog left ventricular midmyocardial myocytes for assessment of drug-induced delayed repolarization: short-term variability and proarrhythmic potential. Br. J. Pharmacol. 159, 77-92.

Bányász, T., Horváth, B., Virág, L., Bárándi, L., Szentandrássy, N., Harmati, G., et al., 2009. Reverse rate dependency is an intrinsic property of canine cardiac preparations. Cardiovasc. Res. 84, 237-244.

Bárándi, L., Virág, L., Jost, N., Horváth, Z., Koncz, I., Papp, R., et al., 2010a. Reverse rate-dependent changes are determined by baseline action potential duration in mammalian and human ventricular preparations. Basic Res. Cardiol. 105, $315-323$.

Bárándi, L., Harmati, G., Horváth, B., Szentandrássy, N., Bányász, T., Magyar, J., et al. 2010b. Drug-induced changes in action potential duration are proportional to action potential duration in rat ventricular myocardium. Gen. Physiol. Biophys. 29, 308-312.

Bers, D.M., 2000. Calcium fluxes involved in control of cardiac myocyte contraction. Circ. Res. 87, 275-281.

Boukens, B.J., Meijborg, V.M.F., Belterman, C.N., Opthof, T., Janse, M.J. Schuessler, R.B., Coronel, R., Efimov, I.R., 2017. Local transmural action potential gradients are absent in the isolated, intact dog heart but present in the corresponding coronary-perfused wedge. Phys. Rep. 5, e13251.

Boyett, M.R., Jewell, B.R., 1978. A study of the factors responsible for rate-dependent shortening of the action potential in mammalian ventricular muscle. J. Physiol. $285,359-380$.

Campbell, T.J., 1983. Kinetics of onset of rate-dependent effects of class I antiarrhythmic drugs are important in determining their effects on refractoriness in Guinea pig ventricle, and provide a theoretical basis for their subclassification. Cardiovasc. Res. 17, 344-352.

Campbell, T.J., 1992. Subclassification of class I antiarrhythmic drugs: enhanced relevance after CAST. Cardiovasc. Drugs Ther. 6, 519-528.

Colatsky, T.J., 1982. Mechanism of action of lidocaine and quinidine on action potential duration in rabbit cardiac Purkinje fibers. Circ. Res. 50, 17-27.

Díaz, M.E., O’Neill, S.C., Eisner, D.A., 2004. Sarcoplasmic reticulum calcium content fluctuation is the key to cardiac alternans. Circ. Res. 94, 650-656.

Echt, D.S., Liebson, P.R., Mitchell, L.B., Peters, R.W., Obias-Manno, D., Barker, A.H. et al., 1991. Mortality and morbidity in patients receiving encainide, flecainide, or placebo - the cardiac arrhythmia suppression trial. N. Engl. J. Med. 324, $781-788$.

Elharrar, V., Surawicz, B., 1983. Cycle length effect on restitution of action potential duration in dog cardiac fibers. Am. J. Physiol. 244, H782-H792, 1983.

Fozzard, H.A., 1992. Afterdepolarizations and triggered activity. Basic Res. Cardiol. 87 (Suppl. 2), 105-113.

Garfinkel, A., Kim, Y.H., Voroshilovsky, O., Qu, Z., Kil, J.R., Lee, M.H., Karagueuzian, H.S., Weiss, J.N., Chen, P.S., 2000. Preventing ventricular fibrillation by flattening cardiac restitution. Proc. Natl. Acad. Sci. U.S.A. 97, 6061-6066, 2000.

Grant, A.O., Starmer, C.F., Strauss, H.C., 1984. Antiarrhythmic drug action. Blockade of the inward sodium current. Circ. Res. 55, 427-438.

Hegyi, B., Horváth, B., Váczi, K., Gönczi, M., Kistamás, K., Ruzsnavszky, F., et al., 2017. $\mathrm{Ca}^{2+}$-activated $\mathrm{Cl}^{-}$current is antiarrhythmic by reducing both spatial and temporal heterogeneity of cardiac repolarization. J. Mol. Cell. Cardiol. 109, 27-37.

Heijman, J., Zaza, A., Johnson, D.M., Rudy, Y., Peeters, R.L.M., Volders, P.G.A., et al., 2013. Determinants of beat-to-beat variability of repolarization duration in the canine ventricular myocyte: a computational analysis. PLoS Comput. Biol. 9 e1003202.

Hille, B., 1977. Local anesthetics. Hydrophilic and hydrophobic pathways for the drug-receptor interaction. J. Gen. Physiol. 69, 497-515.

Hinterseer, M., Thomsen, M.B., Beckmann, B.M., Pfeufer, A., Schimpf, R., Wichmann, et al., 2008. Beat-to-beat variability of QT intervals is increased in patients with drug-induced long-QT syndrome: a case control pilot study. Eur. Heart J. 29 185-190.

Hinterseer, M., Beckmann, B.M., Thomsen, M.B., Pfeufer, A., Dalla Pozza, R., Loeff, M. et al. 2009. Relation of increased short-term variability of OT interval to congenital long-QT syndrome. Am. J. Cardiol. 103, 1244-1248.

Hinterseer, M., Beckmann, B.M., Thomsen, M.B., Pfeufer, A., Ulbrich, M., Sinner, M.F. et al., 2010. Usefulness of short-term variability of QT intervals as a predictor for electrical remodeling and proarrhythmia in patients with nonischemic heart failure. Am. J. Cardiol. 106, 216-220.

Hoffmann, B.F., Rosen, M.R., 1981. Cellular mechanisms for cardiac arrhythmias. Circ. Res. 49, 1-15.

Hondeghem, L.M., Katzung, B.G., 1977. Time- and voltage-dependent interactions of antiarrhythmic drugs with cardiac sodium channels. Biochim. Biophys. Acta $472,373-398$

Hondeghem, L.M., Katzung, B.G., 1984. Antiarrhythmic agents: the modulated receptor mechanism of action of sodium and calcium channel-blocking drugs Annu. Rev. Pharmacol. Toxicol. 24, 387-423.
Hondeghem, L.M., Matsubara, T., 1988. Quinidine blocks cardiac sodium channels during opening and slow inactivation in Guinea pig papillary muscle. Br. J. Pharmacol. 93, 311-318.

Hondeghem, L.M., Snyders, D.J., 1990. Class III antiarrhythmic agents have a lot of potential but a long way to go. Reduced effectiveness and dangers of reverse use dependence Circulation 81, 686-690.

Horváth, B., Váczi, K., Hegyi, B., Gönczi, M., Dienes, B., Kistamás, K., et al., 2016. Sarcolemmal $\mathrm{Ca}^{2+}$-entry through L-type $\mathrm{Ca}^{2+}$ channels controls the profile of $\mathrm{Ca}^{2+}$-activated $\mathrm{Cl}^{-}$current in canine ventricular myocytes. J. Mol. Cell. Cardiol. 97, 125-139.

Jacobson, I., Carlsson, L., Duker, G., 2011. Beat-by-beat QT interval variability, but not QT prolongation per se, predicts drug-induced torsades de pointes in the anaesthetised methoxamine-sensitized rabbit. J. Pharmacol. Toxicol. Methods 63, 40-46.

Johnson, D.M., Heijman, J., Pollard, C.E., Valentin, J.P., Crijns, H.J., Abi-Gerges, N., et al., 2010. IKs restricts excessive beat-to-beat variability of repolarization during beta-adrenergic receptor stimulation. J. Mol. Cell. Cardiol. 48, 122-130.

Johnson, D.M., Heijman, J., Bode, E.F., Greensmith, D.J., Van der Linde, H., Abi-Gerges, et al., 2013. Diastolic spontaneous calcium release from the sarcoplasmic reticulum increases beat-to-beat variability of repolarization in canine ventricular myocytes after $\beta$-adrenergic stimulation. Circ. Res. 112, 246-256.

Jurkiewicz, N.K., Sanguinetti, M.C., 1993. Rate-dependent prolongation of cardiac action potentials by a methanesulfonanilide class III antiarrhythmic agent specific block of rapidly activating delayed rectifier $\mathrm{K}^{+}$current by dofetilide. Circ. Res. 72, 75-83.

Kistamás, K., Szentandrássy, N., Hegyi, B., Váczi, K., Ruzsnavszky, F., Horváth, B., et al., 2015a. Changes in intracellular calcium concentration influence beat-tobeat variability of action potential duration in canine ventricular myocytes. J. Physiol. Pharmacol. 66, 73-81.

Kistamás, K., Hegyi, B., Váczi, K., Horváth, B., Bányász, T., Magyar, J., et al., 2015b. Oxidative shift in tissue redox potential increases beat-to-beat variability of action potential duration. Can. J. Physiol. Pharmacol. 93, 527-534.

Lemay, M., de Lange, E., Kucera, J.P., 2011. Effects of stochastic channel gating and distribution on the cardiac action potential. J. Theor. Biol. 281, 84-96.

Lemoine, M.D., Krause, T., Koivumäki, J.T., Prondzynski, M., Schulze, M.L., Girdauskas, E., Willems, S., Hansen, A., Eschenhagen, T., Christ, T., 2018. Human induced pluripotent stem cell-derived engineered heart tissue as a sensitive test system for QT prolongation and arrhythmic triggers. Circ Arrhythm Electrophysiol 11 (7), e00603.

Lengyel, Cs, Varró, A., Tábori, K., Papp, J.Gy, Baczkó, I., 2007. Combined pharmacological block of $\mathrm{I}_{\mathrm{Kr}}$ and $\mathrm{I}_{\mathrm{Ks}}$ increases short-term QT interval variability and provokes torsades de pointes. Br. J. Pharmacol. 151, 941-951.

Magyar, J., Bányász, T., Szentandrássy, N., Kistamás, K., Nánási, P.P., Satin, J., 2015. Role of gap junction channel in the development of beat-to-beat action potential repolarization variability and arrhythmias. Curr. Pharmacol. Design 21, $1042-1052$

Magyar, J., Kistamás, K., Váczi, K., Hegyi, B., Horváth, B., Bányász, T., et al., 2016. Concept of relative variability of cardiac action potential duration and its test under various experimental conditions. Gen. Physiol. Biophys. 35, 55-62.

Morgan, J.M., Cunningham, D., Rowland, E., 1992. Dispersion of monophasic action potential duration: demonstrable in humans after premature ventricular extrastimulation but not in steady state. J. Am. Coll. Cardiol. 19, 1244-1253, 1992.

Mulla, W., Gillis, R., Murninkas, M., Klapper-Goldstein, H., Gabay, H., Mor, M., Elyagon, S., Liel-Cohen, N., Bernus, O., Etzion, Y., 2018. Unanesthetized rodents demonstrate insensitivity of QT Interval and ventricular refractory period to pacing cycle length. Front. Physiol. 9, 897. https://doi.org/10.3389/ fphys.2018.0089.

Nair, L.A., Grant, A.O., 1997. Emerging class III antiarrhythmic agents: mechanism of action and proarrhythmic potential. Cardiovasc. Drugs Ther. 11, 149-167.

Nánási, P.P., Pankucsi, C., Bányász, T., Szigligeti, P., Papp, J.G., Varró, A., 1996. Electrical restitution in rat ventricular muscle. Acta Physiol. Scand 158 (2),143-153.

Nash, M.P., Bradley, C.P., Sutton, P.M., Clayton, R.H., Kallis, P., Hayward, M.P., Paterson, D.J., Taggart, P., 2006. Whole heart action potential duration restitution properties in cardiac patients: a combined clinical and modelling study. Exp. Physiol. 91, 339-354, 2006.

Ni, H., Zhang, H., Grandi, E., Narayan, S.M., Giles, W., 2018. Transient outward K+ current can strongly modulate action potential duration and initiate alternans in human atrium. Am. J. Physiol. Heart Circ. Physiol. 316, H527-H542, 2018.

Osadchii, O.E., 2017. Role of abnormal repolarization in the mechanism of cardiac arrhythmia. Acta Physiol. 712, 1-71, 2017.

Pak, H.N., Hong, S.J., Hwang, G.S., Lee, H.S., Park, S.W., Ahn, J.C., Ro, Y.M., Kim, Y.H., 2004. Spatial dispersion of action potential duration restitution kinetics is associated with induction of ventricular tachycardia/fibrillation in humans. J. Cardiovasc. Electrophysiol. 15, 1357-1363.

Pastore, J.M., Girouard, S.D., Laurita, K.R., Akar, F.G., Rosenbaum, D.S., 1999. Mechanism linking T-wave alternans to the genesis of cardiac fibrillation. Circulation 99, 1385-1394, 1999.

Pruvot, E.J., Katra, R.P., Rosenbaum, D.S., Laurita, K.R., 2004. Role of calcium cycling versus restitution in the mechanism of repolarization alternans. Circ. Res. 94, 1083-1090.

Pueyo, E., Corrias, A., Virág, L., Jost, N., Szél, T., Varró, A., et al., 2011. A multiscale investigation of repolarization variability and its role in cardiac arrhythmogenesis. Biophys. J. 101, 2892-2902.

Riccio, M.L., Koller, M.L., Gilmour, R.F., 1999. Electrical restitution and 
spatiotemporal organization during ventricular fibrillation. Circ. Res. 84, 955-963, 1999.

Robinson, R.B., Boyden, P.A., Hoffman, B.F., Hewett, K.W., 1987. Electrical restitution process in dispersed canine cardiac Purkinje and ventricular cells. Am. J. Physiol. 253, H1018-H1025, 1987.

Rocchetti, M., Besana, A., Gurrola, G.B., Possani, L.D., Zaza, A., 2001. Rate dependency of delayed rectifier currents during the Guinea-pig ventricular action potential. J. Physiol. 534, 721-732.

Shattock, M.J., Park, K.C. Yang, H.Y., Lee, A.W.C., Niederer, S., MacLeod, K.T., Winter, J., 2017. Restitution slope is principally determined by steady-state action potential duration. Cardiovasc. Res. 113, 817-828, 2017.

Starmer, C.F., Grant, A.O., 1985. Phasic ion channel blockade. A kinetic model and parameter estimation procedure. Mol. Pharmacol. 28, 348-356.

Starmer, C.F., Grant, A.O., Strauss, H.C., 1984. Mechanism of use-dependent block of sodium channels in excitable membranes by local anesthetics. Biophys. J. 46, $15-27$.

Sur, S., Han, L., Tereshchenko, L.G., 2013. Comparison of sum absolute QRST integral, and temporal variability in depolarization and repolarization, measured by dynamic vectorcardiograpy approach, in healthy men and women. PLoS One 8 (2), e57175.

Szentandrássy, N., Kistamás, K., Hegyi, B., Horváth, B., Ruzsnavszky, F., Váczi, K., et al., 2015. Contribution of ion currents to beat-to-beat variability of action potential duration in canine ventricular myocytes. Pflüg. Arch. 467, 1431-1443.

Tereshchenko, L.G., Han, L., Cheng, A., Marine, J.E., Spragg, D.D., Sinha, S., et al., 2010. Beat-to-beat three-dimensional ECG variability predicts ventricular arrhythmia in ICD recipients. Heart Rhythm 7, 1606-1613.

Thomsen, M.B., Verduyn, S.C., Stengl, M., Beekman, J.D., de Pater, G., van Opstal, J. et al., 2004. Increased short-term variability of repolarization predicts $d$-sotalolinduced torsades de pointes in dogs. Circulation 110, 2453-2459.

Thomsen, M.B., Volders, P.G.A., Beekman, J.D., Matz, J., Vos, M.A., 2006. Beat-to-beat variability of repolarization determines proarrhythmic outcome in dogs susceptible to drug-induced torsades de pointes. J. Am. Coll. Cardiol. 48, $1268-1276$.

Tolkacheva, E.G., Anumonwo, J.M.B., Jalife, J., 2006. Action potential duration restitution portraits of mammalian ventricular myocytes: role of calcium current. Biophys. J. 91, 2735-2745.
Van der Linde, H., Van de Water, A., Loots, W., Van Deuren, B., Lu, H.R., Van Ammel, K., et al., 2005. A new method to calculate the beat-to-beat instability of QT duration in drug-induced long QT in anesthetized dogs. J. Pharmacol. Toxicol. Methods 52, 168-177.

Varro, A., Elharrar, V., Surawicz, B., 1985. Effect of antiarrhythmic drugs on the premature action potential duration in canine cardiac Purkinje fibers. J. Pharmacol. Exp. Ther. 233 (2), 304-311.

Virág, L., Acsai, K., Hála, O., Zaza, A., Bitay, M., Bogáts, G., et al., 2009. Self augmentation of the lengthening of repolarization is related to the shape of the cardiac action potential: implication for reverse rate dependency. Br. J. Pharmacol. 156, 1076-1084.

Waldo, A.L., Camm, A.J., deRuyter, H., Freidman, P.L., MacNeil, D.J., Pitt, B., et al., 1995 Survival with oral d-sotalol in patients with left ventricular dysfunction after myocardial infarction: rationale, design, and methods (The SWORD Trial). Am. J. Cardiol. 75, 1023-1027.

Weirich, J., Antoni, H., 1998. Rate-dependence of antiarrhythmic and proarrhythmic properties of class I and class III antiarrhythmic drugs. Basic Res. Cardiol. 93 (Suppl. 1), 125-132.

Weiss, J.N., Nivala, M., Garfinkel, A., Qu, Z., 2011. Alternans and arrhythmias: from cell to heart. Circ. Res. 108, 98-112, 2011.

Weiss, J.N., Garfinkel, A., Karagueuzian, H.S., Nguyen, T.P., Olcese, R., Chen, P.S. Qu, Z., 2015. Perspective: a dynamics-based classification of ventricular arrhythmias. J. Mol. Cell. Cardiol. 82, 136-152.

Wu, T.J., Lin, S.F., Weiss, J.N., Ting, C.T., Chen, P.S., 2002. Two types of ventricular fibrillation in isolated rabbit heart. Importance of excitability and action potential duration restitution. Circulation 106, 1859-1866.

Yang, T., Roden, D.M., 1996. Extracellular potassium modulation of drug block of IKr. Implications for torsade de pointes and reverse use-dependence. Circulation 93, 407-411.

Zaniboni, M., Pollard, A.E., Yang, L., Spitzer, K.W., 2000. Beat-to-beat repolarization variability in ventricular myocytes and its suppression by electrical coupling. Am. J. Physiol. Heart Circ. Physiol. 278, H677-H687.

Zaza, A., 2010. Control of the cardiac action potential: the role of repolarization dynamics. J. Mol. Cell. Cardiol. 48, 106-111.

Zaza, A., Varró, A., 2006. Rate-dependent modulation of repolarization: biology or math? (Abstract). Eur. Heart J. 27, 412. 